\title{
Effect of Cypermethrin (10\%E.C) On Oxygen Consumption and Histopathology of Freshwater Fish Cirrhinus Mrigala (Hamilton)
}

\author{
Manjula Sree Veni $\mathrm{S}^{1}$ and Veeraiah $\mathrm{k}^{2}$ \\ ${ }^{1}$ Department of Zoology Noble College, Machilipatnam. \\ ${ }^{2}$ Department of Zoology, Acharya Nagarjuna University, Guntur.
}

\begin{abstract}
Generally pesticide concentrations are toxic which may be lethal (or) sublethal concentration in aquatic environment. Lethal concentration cause death of the organisms directly, but the sub lethal concentrations are too low to cause rapid death directly. O xygen consumption of an animal are the important physiological parameters to assess the toxic stress because it is a valuable indicators of energy expenditure in particular and metabolism in general. Exposure to sublethal concentrations is reported to increase respiratory activity, resulting in increased Ventilation and hence increased uptake of the toxicant. Although, toxicant impairs the metabolic and physiological activities of the organisms, physiological studies alone do not satisfy the complete under toxic stress. Hence it is useful to have an insight in to the histological analysis. The extent of severity of tissue damage is a consequence of the concentration of the toxicant and is time dependent. Also, the severity of damage depends on the toxic potentiality of a particular compound or pesticide accumulated in the tissue. The total oxygen Consumption is one of the indicators of the general well being of the fish. Hence the differential oxygen Consumption can be used as bio-indicator to evaluate the basic damage inflicted on the animal which could either increase (or) decrease the oxygen uptake and histopathological changes in certain vital tissues like gill, liver and kidney of the Indian major Carp Cirrhinus mrigala exposed to sublethal concentrated (1/10 of 96 hrs LC 50).
\end{abstract}

Key Words: Oxygen consumption, histopathology cirrhinus mrigala Cypermethrin,

\section{Introduction}

In aquatic environment, One of the most important manifestations of toxic action of Chemicals is the over stimulaltion (or) depression of respiratory activity. (Muirhead, Thomson 1971) the respiratory potential and oxygen consumption of an animal are the important physiological parameters to assess the toxic stress because it is a valuable indicators of energy expenditure in particular and metabolism in general. (Klein 1959 and Jones 1964). Pesticides enter into the body of fish mainly through gills and with the onset of symptoms of poisoning, the rate of oxygen consumption increases Holden,(1962), Premdas and Anderson. (1982), Ferguson et al (1966), Holden (1973). He observed that one of the earliest symptoms of acute pesticide poisoning is respiratory distress.

Although these investigations have proved to be very useful in describing responses to sub lethal exposure and have direct implications for mode of action, the interpretations of the ecological significance of these numerous respiratory responses remain difficult. The changes in the respiratory activity of fish and aquatic micro-invertebrates have been used by several investigators.Exposure to sublethal concentrations is reported to increase respiratory activity, resulting in increased Ventilation and hence increased uptake of the toxicant. OCs have been reported to stimulate Oxygen consumption at sublethal Concentrations and inhibit the oxygen uptake at lethal Concentrations. In the case of synthetic pyrethroids a steady and progressive decline in Ventilatory pattern and these by decline in oxygen Consumption is noticed.(Veeraiah and Durga Prasad 2001). However there have been exceptions to this statement and it is difficult to generalize (Murty 1986).

The total oxygen Consumption is one of the indicators of the general well being of the fish. It may be also useful to assess the Physiological State of an organism helps in evaluating the susceptability and resistance potentiality and also useful to Correlate the behaviour of the organism which Ultimately serve as indicator of functional disruption of population Hence the differential oxygen Consumption can be used as bio-indicator to evaluate the basic damage inflicted on the animal which could either increase (or )decrease the oxygen uptake. Hence an attempt has been made to study the effect of sub-lelthal and lethal concentrations of cypermethrin $10 \% \mathrm{EC}$ on oxygen consumption for 12 hours at two hour interval to the Indian major carp cirrhinus mrigala (Hamilton).

\section{Materials And Method}

The fish cirrhinus mrigala 5-6cm in lenth and 3-4 gm in weight were brought from a local fish farm and acclimatized to the laboratory conditions in well aerated water for one week.The water used for acclimatization and experimentation was same as used in the toxicity experiments. During acclimatization 
period, fish were fed regularly, but the feeding was stopped for two days prior to the experiment .The experiments on the oxygen consumption of the fish were carried out in a respiratory apparatus developed by job (1955).Fish were exposed to sub-lethal concentrations of cypermethrin for 4 days .At the end of the exposure period, fish were randomly selected for histopathological examination. Gills alone were processed by double Sections were cut at 6 Microns thickness, stained with Ehrlich haematoxillin and Eosin (dissolved in 70\% alcohol) (Humason,1972) and were mounted in Canadabalsam

\section{Results And Discussion}

The comparative data on the whole animal oxygen consumption of control and experimental fish , calculated per gram body weight in lethal and sublethal concentrations of cypermethrin 10\% EC formulation for the fish Cirrhinus mrigala. A comparison is made between the controls and sub lethal concentrations of cypermethrin 10\% EC to the fish Cirrrhinus mrigala for every 2 hrs. A steady state of decrease in oxygen consumption in sub lethal concentration of toxicant is inevitable. Similarly in lethal concentrations of cypermethrin $10 \%$ E.C, in cirrhinus mrigala steady state of decrease in oxygen consumption was observed through out the experimental period.

In controls also, the rate of oxygen consumption was gradually decreased and this can be attributed to the starved conditions and the reduced metabolic rates of the starved fish. The cirrhinus mrigala fish, bottom feeder is acclimatized to low oxygen concentration hence showing least indices in pesticide toxicity. The fish are in more stress during first hour and later they are showing signs of recovery. That recovery is evident as the toxicant exposure is increased in time during 12 hours experiment. Throughout the experimental period the fish showed severe respiratory distress and rapid opercular movements leading to the higher amount of toxicant uptake, increased mucous secretion, higher ventilation volume, decrease in oxygen uptake efficiency, laboured breathing and engulfing of air through the mouth when exposed to cypermethrin $10 \% \mathrm{EC}$.

O'Brien (1967) found that pesticides were observed to cause respiratory distress (or ) even failure by affecting respiratory centres of the brain (or) tissue involved in breathing. The amount of oxygen consumption by the intact of animal reflects its total metabolic rate and hence the energy output. Changes in the architecture of gill under cypermethrin stress would alter the diffusing capacity of gill with consequent hypoxic/anoxic conditions, thus, respiration may become a problematic task for the fish. These results suggest that the altered rates of respiration of fresh water fish may also serve as a rapid biological monitor to assess the impact of pesticide on other biotic communities in the water body. Hypoxic and anoxic condition was prevalent in the aquatic environment during the Cambrian period, owing to the low atmosphere oxygen levels at that time. (Randall et al, 1981, Almeida-Val et al.,1999). All the studies mentioned above indicate a considerable effect of insecticides concentrations. The present study revealed alterations in the oxygen consumption of cirrhinus mrigala exposed to sub lethal and lethal concentrations of cypermethrin, a synthetic pyrethroid compound.

Table:

The amount of oxygen Consumed in $\mathrm{mg} / \mathrm{g}$ body weight/hr of the freshwater fish Cirrhinus Mrigala Exposed to lethal and sub-lethal concentrations of cypermethrin $10 \% \mathrm{EC}$

\begin{tabular}{|l|l|l|l|l|}
\hline S.no & $\begin{array}{l}\text { Hours of } \\
\text { exposure }\end{array}$ & Control & Sub-Lethal & Lethal \\
\hline 1 & 0 & $\begin{array}{l}1.236 \\
+/-0.3677\end{array}$ & $\begin{array}{l}1.176 \\
+/-0.1537\end{array}$ & $\begin{array}{l}1.184 \\
+/-0.1214\end{array}$ \\
\hline 2 & 2 & $\begin{array}{l}1.132 \\
+/-0.1281\end{array}$ & $\begin{array}{l}1.098 \\
+/-0.8010\end{array}$ & $\begin{array}{l}1.118 \\
+/-0.1151\end{array}$ \\
\hline 3 & 4 & $\begin{array}{l}0.914 \\
+/-0.1718\end{array}$ & $\begin{array}{l}0.912 \\
+/-0.0858\end{array}$ & $\begin{array}{l}0.992 \\
+/-0.0740\end{array}$ \\
\hline 4 & 6 & $\begin{array}{l}0.856 \\
+/-0.1137\end{array}$ & $\begin{array}{l}0.850 \\
+/-0.0607 \\
+/-0.0543\end{array}$ \\
\hline 5 & 8 & $\begin{array}{l}0.758 \\
+/-01146\end{array}$ & $\begin{array}{l}0.758 \\
+/-0.0828\end{array}$ & $\begin{array}{l}0.682 \\
+/-0.0259\end{array}$ \\
\hline 6 & 10 & $\begin{array}{l}0.598 \\
+/-0.0801\end{array}$ & $\begin{array}{l}0.740 \\
+/-0.0439\end{array}$ & $\begin{array}{l}0.486 \\
+/-0.0274\end{array}$ \\
\hline 7 & 12 & $\begin{array}{l}0.418 \\
+/-0.0639\end{array}$ & $\begin{array}{l}0.652 \\
+/-0.0356\end{array}$ & $\begin{array}{l}0.410 \\
+/-0.0211\end{array}$ \\
\hline
\end{tabular}

Each value is mean of 5 individiual observations (+/-) indicates standard deviation values in the brackets indicate percent decrease over contr 


\section{Figure:}

The amount of oxygen consumed in $\mathrm{mg} / \mathrm{g}$ body weight to the fish cirrhinus mrigala exposed to sub lethal and lethal concentrations of cypermethrin $10 \% \mathrm{EC}$

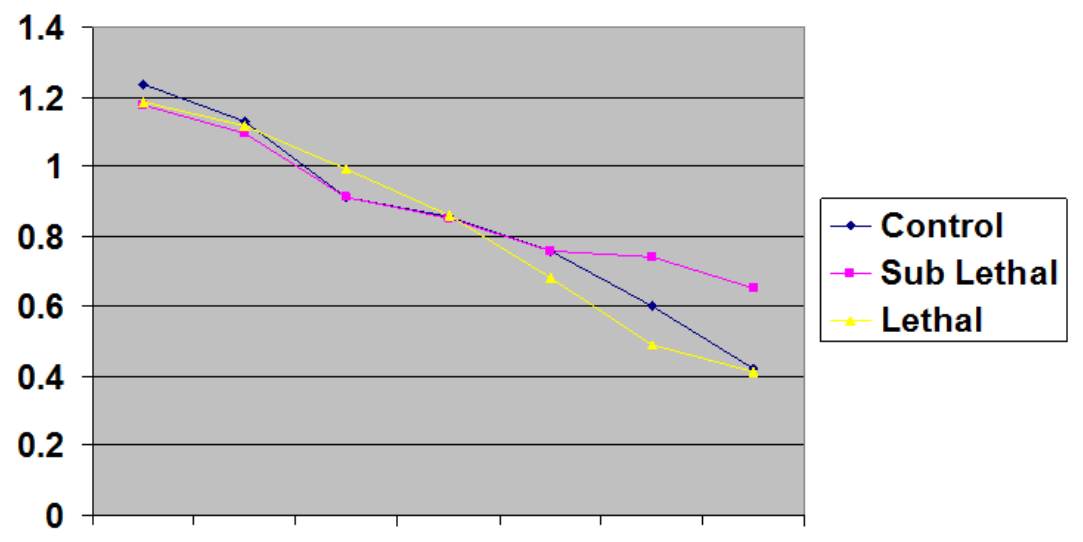

\section{Hours of exposure}

$$
\begin{array}{lllllll}
2 & 4 & 6 & 8 & 10 & 12
\end{array}
$$

\section{Histopathology}

Susceptibility of animal tissue to different chemical agents may from animal to animal and also with the same animal among the different tissues of the individual, incorporation of the parent and/or their metabolites in lower organisms, in the tissues of fishes, birds, and mammals have been recorded to cause serious morphological alterations in vital tissues even at the very low concentrations (Chakraburthy and Konar, 1974; Mathur et al, 1984). The toxicity of any toxicant is either acute or chronic. The chronic studies include both histochemistry and pathology. Although, toxicant impairs the metabolic and physiological activities of the organisms, physiological studies alone do not satisfy the complete under toxic stress. Hence it is useful to have an insight in to the histological analysis. The extent of severity of tissue damage is a consequence of the concentration of the toxicant and is time dependent. Also, the severity of damage depends on the toxic potentiality of a particular compound or pesticide accumulated in the tissue (Jayantha rao, 19840.Aquatic vertebrates' are susceptible to non target effects, because of their relatively restricted mobility ,due to reduced pesticide dispertion leading to lengthy periods of exposure (Smith and Strattar , 1986).

Fishes are particularly sensitive to a wide variety of pesticide chemicals.and toxic concentrations may raise not only from spillage of agricultural practices if their use is excessive but also from several other sources. Apart from causing death either directly or due to starvation by distraction of food organisms, many pesticides have been shown to effect growth rate, reproduction, and behavior with the evidence of tissue damage. Although toxicant impairs the metabolic physiological activities of the organisms, physiological studies alone do not satisfy the complete understanding of pathological conditions of the tissue under toxic stress. Hence it is useful to have insight in to histological analysis. The extent of severity of tissue damage is a consequence of the concentration of toxicant and is time dependent. Also severity of damage dependent on the toxic potentiality of a particular compound, or pesticide accumulated in the tissue (jayantha Rao, 1984)

.In the present study , an attempt has been made to observe possible histopathological changes in certain vital tissues like gill, liver and kidney of the Indian major Carp Cirrhinus mrigala exposed to sublethal concentrated (1/10 of $96 \mathrm{hrs} \mathrm{LC} \mathrm{50)} \mathrm{of} \mathrm{cypermethrin} \mathrm{10 \%} \mathrm{EC} \mathrm{for} 4$ days. The nutritional gill disease consists of lamellar epithelial hyperplasia with eventual fusion of secondary lamellae near the tips of the gill filaments (Cowry and Roberts, 1978 ). The biological function of the inflammatory response is to destroy "WALL OFF " Iritating substance so that damaged tissue may be healed. A number of pathological changes have been reported in fish exposed different organochlorine and organophosphates and synthetic pyrethroid compounds. Exposure of "Sockeye " salmon fry to the butoxy ethyl ester of 2, 4- D for $96 \mathrm{hrs} \mathrm{(} 1 \mathrm{mg} / 1$ ) resulted in hypertrophy and hyperplasia of the epithelial cells of the gills (Mc Bride , 1981), Eller (1971) described endrin induced histopathological changes in cut throat trout and reviewed the gill lesions in fresh water teleosts. The other reports on these lines to different pesticides are Lowe , (1966 ),Konar ,(1979 ),Natarajan, (1981):Jayantha Rao et al, (1985 ); Girija, (1987); Rama Murthy, (1988 ); Vijayalakshmi and Tilak (1996); Tilak et al (2001a); Tilak et al (2001b); Tilak et al (2002); Tilak et al (2005,2 007), and venkatesam and subramaniam (2007). Baticodos et al., (1991) reported slight hyperplasia of gill epithelium in Pinaes monodon exposed to gusathion, a commonly used organophosphates inflammatory alterations of lamellar epithelium and hyperplasia were reported in the gills of Fresh water major carp Cirrhinus mrigala (Hamilton) 


\section{General Histology of Fish Gill:}

\section{Results And Discussion}

Teleosts have five pairs of gill arches. In the front four pairs, the slender gill filaments form two lines facing towards the back, and these two lines are joined to each other at the base by a gill septum. The last pair of gill arches generally transforms into the pharyngeal bone and does not play a role in respiration.

Numerous semicircular secondary gill lamellae are lined up along both sides of the gill filaments. The surface of the gill lamellae is covered with simple squamous epithelial cells and many capillaries separated by pillar cells run parallel along the surface. Numerous semicircular secondary gill lamellae are lined up along both sides of the primary gill lamellae (plate 1,2,3, Fig. 1.). The primary gill lamellae consists of centrally placed rod like supporting axis (SA) with blood vessels on either side. The secondary lamellae, also termed as respiratory lamellae (RL), are highly vascularised and covered with a thin layer of epithelial cells (EC), blood vessels (BV) are extended into each of the secondary gill filaments. The blood cells of the secondary gill lamellae have a single nucleus which are flattened in appearance. The region between the two adjacent secondary gill lamellae is known as inter lamellar region.

\section{Pathology of Gill under cypermethrin toxicity:}

cypermethrin $10 \%$ EC has induced marked pathological changes in fish gill. The changes include the bulging of tips primary gill filaments. The secondary gill filaments lost their original shape and curling of secondary gill filaments was also observed. pillar cell nucleus showed necrosis and development of vacuoles in the secondary gill epithelium. There is a tendency of fusion of disorganized secondary gill filaments (Plate 1. Fig . 2..3).The damage of fish gill exposed to the higher concentrations (Lethal doses) were severe. Shortened and clubbing of the secondary gill lamellae, fusion of adjacent secondary gill lamellae and necrosis in the primary lamellae were also significant (Plate 1. Fig.3 ).

The epithelial layer of secondary lamellae of gill of fish forms a barrier between the fish blood and surrounding water. Gaseous exchange needed to sustain life life takes place through their barrier and any thickening induced by physical, chemical or biological agents hinders the respiratory function of this organ ( Eller , 1971).In fish, gill is the first organ to which the pollutant comes in to contact. Hence it is more vulnerable to damage than any other tissue. The proliferative gill lesions are often observed after exposure of the fish to water soluble toxicants. The nutritional gill disease consists of lamellar epithelial hyperplasia with eventual fusion of secondary lamellae near the tips of the gill filaments (Cowry and Roberts, 1978). The biological function of the inflammatory response is to destroy "WALL OFF" Iritating substance so that damaged tissue may be healed. A number of pathological changes have been reported in fish exposed different organochlorine and organophosphates and synthetic pyrethroid compounds. Exposure of "Sockeye " salmon fry to the butoxy ethyl ester of 2, 4- D for $96 \mathrm{hrs}(1 \mathrm{mg} / 1)$ resulted in hypertrophy and hyperplasia of the epithelial cells of the gills (Mc Bride, 1981), Eller (1971) described endrin induced histopathological changes in cut throat trout and reviewed the gill lesions in fresh water teleosts. The other reports on these lines to different pesticides are Lowe, (1966),Konar ,(1979 ),Natarajan, (1981):JayanthaRao et al, (1985);Girija, (1987); Rama Murthy, (1988 ); Vijayalakshmi and Tilak (1996); Tilak et al (2001a); Tilak et al (2001b); Tilak et al (2002); Tilak et al (2005,)venkatesam and subramaniam, (2007). exposure to sublethal dose of malathion (Ray and Datta, ( 1991).Edema with lifting of lamellar epithelium and hyperplasia.

Baticodos et al. , (1991) reported slight hyperplasia of gill epithelium in pinaes monodon exposed to gusathion, a commonly used organophosphates inflammatory alterations of lamellar epithelium and hyperplasia were reported in the gills of Fresh water major carp Cirrhinus mrigala (Hamilton) $48 \mathrm{hrs}$ exposure to sublethal dose of malathion (Ray and Datta, ( 1991).Edema with lifting of lamellar epithelium and hyperplasia of lamellar epithelium were observed in the gills of all cat fish containing residues of endosulfan (Nowak and Barbara, 1992).Similar findings were noted in the gills of rainbow trouton exposure to zinc sulphate by Skidmore and Tovell (1972), Kuruppasamy,(2000). Sakar.et al ,(2005), Tilak et al (2005), Sunitha and Sahai (1983) reported swellings of inflammation in almost all the respiratory lamellae of gills of Rasbora daniconius on exposure to $\mathrm{HCH}$.

Anitha kumari and Shree Ram Kumar (1997) observed decreased carbohydrate activity in the secondary lamellae and also in the respiratory epithelium of the Fresh water teleost Channa punctatus under exposure to the polluted water of Hussain Sagar and states that the degeneration of respiratory epithelium and damage of gill tissue causes a decrease in energy metabolism. Hyperplasia of gill filaments fusion of gill filaments due to separation of epithelium, necrosis of gill epithelium,degeneration of pillar cells, deveiopment of vacuoles in the epithelium are the pathological changes observed in Aluminium Chloride exposed fish. Similar changes were observed in rainbow trout exposure to sublethal dose of monocrotophos (Vijayalakshmi, 1994) ,to fenvalerate in Labeo Rohita by );); to cypermethrin in Labeo Rohita (Veeraiah 2001), Copper sulphate in Oreochromis mossambicus Venkatesam and Subramaniam ,(2007),Butachlor and Machete in Channa punctatus Tilak et al ., (2007).In the present study also several changes were pathological 
changes were observed which were reported by several author in different fishes under exposure to different pesticides and other pollutants.

\section{General Histology of Liver:}

Hepatic cells have many vital functions. Other than the secretion of bile, they play an important role in protein, lapid and carbohydrate metabolism. They serve as storage sites for some nutrients and detoxification is an another function attributed to them. The surface of liver is covered with serous membrane and some connective tissue extends inward into parenchyma. It is composed of parenchymal cells (hepatic cells) and lattice fibres, which support the former. Hepatic cells are roundish polygonal, containing clear spherical nucleus. They are located among sinusoids forming cord like structures known as hepatic cell cords. In fish, these structures are generally obscure. Bile canaliculus, is centrally located in each cord. Fairly large quanitities of lipid glycogen granules are also observed in the cytoplasm of fish hepatic cells. (Plate .2, Fig.1).

\section{Pathology of Liver tissue under cypermethrin toxicity:}

cypermethrin has induced discrete pathological changes in of Liver tissue of the fish Cirrhinus mrigala. These changes include degeneration of cytoplasm in hepatocytes ,atropy, formation of vacuoles rupture in blood vessels, necrosis and disappearance of hepatocytic cell wall and disposition of hepatic cords (Plate .2 Fig 2.3).Liver is the first organ to face any foreign molecule through portal circulation is subjected to more damage (Jayantha Rao ,1982). Liver is an organ of detoxification which breaks down toxic substances and metabolites of administered substances. This breakdown is carried out by endoplasmic reticulam of hepatocytes. Due these reasons the hepatic cells are damaged severely. Mathur (1965) reported that in fish Ophiocephalus punctatus exposed to the toxicant resulted in vaculation and necrosis in liver. Dubale and Shah (1979) reported that Channa punctatus under malathion toxicity showed that degenerative changes in liver. Rashatwar and IIysas (1984)reported that in teieost fish Nemachelius denesoni (Day) exposure to phasphamidon caused highly vacuolated and cloudy swelling and even the connective tissue was damaged in liver. Ansari et al., (1987) reported significant alterations in the hepatic cell count and the nucleocytoplasmic index in the liver of Zebra fish Brachydanio rerio (cyprinid) exposed to $0.9 \mathrm{mg} / 1$ concentration of malathion. A few other reports are available which deal with other than organo phosphate pesticide effect on histology. Cruz (1989) reported that formalene treatment caused cloudy swelling, haemorrhage, deposition of pigments and necrosis in liver of milk fish chanos fingerlings. Radhaiah and Jayatha Rao (1992) reported moderate cytoplasmic degeneration in hepatocytes, formation of vacuoles, rupture in blood vessels and appearance of blood cells among hepatocytes, picnotic nuclei in the liver of T.mossambica exposed to fenvalerate. Similar changes were observed in three Indian major carps catla catla, labeo rohita and, Cirrhinus mrigala exposed to fenvalerate by Anita Susan (1994) and Vijayalakshmi (1994) observed the same changes in labeo rohita under fenvalerate and monocrotophos exposure. Anitha kumara and Sree Ram Kumar (1997)observed an un even distribution of carbohydrate content and a drastic decrease in the hepatic cells of the fresh water Teleosts upon exposure to polluted waters of Hussain Sagar Lake. Tilak et al (2001a, 2001b) (2005) and (2007) reported the same degenerative changes in catla catla Labeo rohita,Ctenopharyngodon idella, and Channa punctatus under chloropyrifos fenvelerate and butachlor toxicities. The degenerative changes are intensified in lethal exposures.They include degeneration of cytoplasm in hepatocytes, atropy, formation of vacuoles, rupture in blood vessels, necrosis and disappearance of hepatocyte wall ,deposition of hepatic cords ,decrease in size of nucleus, pycnotic and vacuolar degeneration within the nucleus was evident (Plate 2 Fig 2.3).

\section{General Histology of Fish Kidney:}

Teleostean kidney consists of head and body kidneys. Head kidney is the anterior portion of the kidney and consists of lymphoid tissue. Body kidney is composed of many nephrons and interstitial limphoid tissue. The interstitial tissue is the major haematopoitic tissue in the body. Each nephron consists of two parts, the glomerulus and the urinary tubule. The glomerulus capsule consists of an inner and outer layer of single flattened epithelia. Renal tubules consist of single layer of epithelial cells. Mesangium fills the space between the loops of glomerular capillaries.

Renal tubules are thin and short in the neck segment, The proximal convoluted segment is divided into two parts i.e. segment I and segment II. The renal tubules are composed of cuboidal epithelial cells with densely arranged microvilli in the tubular lumen. In segment II, renal tubules are composed of cuboidal epithelial cells. Cilia and Microvilli are found in the tubular lumen. In the distal convoluted segment, epithelial cells have no microvilli. The cells of this segment are stained with eosin more faintly than those of proximal convoluted segment (Plate V.3.Fig.1) . Thus, it is easy to distinguish between proximal and distal convoluted segments under light microscopy (Oguri, 1982). 


\section{Pathology of Kidney tissue under cypermethrin toxicity :}

Renal tissues of the fish Cirrhinus mrigala under cypermethrin toxicity evidenced marked pathological changes.Highly degenerative changes were observed in haemopoitic tissue which include severe necrosis ,cloudy swelling in renal tubules, cellular hypertrophy and granular cytoplasm. The epithelial cells of distal convoluted tubules decreased in size. The interstitial renal tissue was less affected. Renal interstitial tissue showed formation of vacuoles and cellular contours were not clearly distinguished (Plate 3 Fig 2 and 3).From the body of fish, the waste products are eliminated through kidney. The non- detoxified pesticide molecules must be eliminated through the kidney of fish and hence, it is susceptible to chemical compounds when exposed to lethal or sublethal dose of cypermethrin $10 \%$ EC While it was eliminated through kidney might have caused degenerative changes in renal tubules and glomeruli, i.e necrosis in the proximal tubule with development of vacuoles (Plate 3 Fig 2.3 ).

Srivatsava and Srivatsava (1982) reported the bursting of glomeruli and tubules and degeneration of cellular boundaries and clumping of glomeruli at some places in the kidney of Cirrhinus mrigala exposed to urea .Cloudy swelling of renal tubule, marked loss of haemopoitic tissue, shrinkage of glomeruli were reported in Namachelius denisoni (Day) exposed to phasphamidon (Rashatwar and llyas , 1984).In monocrotophos treated mice thickening of glomerular basement membrane ,tubular degeneration and compensatory dilation and the fecal collection of chronic inflammatory cells in the interstitial tissue were reported by Malaya Guptha et al,(1988). Degenerative changes in epithelial cells of proximal tubules and haemopoitic tissue ,severe necrosis in the proximal tubules leading to the formation of vacuoles, degenerative changes in epithelial cells of collecting tubules of the Tilapia mossambica exposed to fenvalerate has been reported by Radhaiah (1988).Cytological break down of glomeruli was reported in kidneys of the stickle back Gasterosteus aculetusa exposed to dissolved cadmium (Oronsaye, 1989). Anitha kumara and SreeRamKumar (1997) observed mild activity of carbohydrates in the cytoplasm, nuclei and luminar border of the proximal distal tubules in the kidney of the the fresh water Teleost Channa punctatus under upon exposure to polluted waters of Hussain Sagar Lake.

The present observations are in agreement with the reports of Goel and Veenagarg,(1980); Mandal and Kulshreshtha, (1980); Dubale and Awasthi, (1982 );Malaya Guptha et al ,(1988); Ramana Kumari ,(1999); Tilak et al (2001a 2001b) and (2002) who observed renal damage, rupture in the glomeruli and reduced renal tubule and its lumen in Channa punctatus eposed to fenvalerate chlorpyriphos and butachlor. Dabb. ElZalabani and Soliman ( 1981), and Feng et al., (1982 ) also reported necrosis in renal epithelium, swelling of mitochondria in the renal tubules in animals administered with methothrin and pyrethrin respectively.Such sort of pathological conditions causing distruction of kidney tissue have been reported under pesticide toxicity by Radhaiah (1985 and 1988); Ramamurthy, (1988); Karuppasamy,(2002); Tilak et al., (2005 ,2007); Venkatesam , (2007). Thus when fish is exposed to cypermethrin $10 \% \mathrm{EC}$, they suffer irreparable architectural changes in various vital organs making the fish less fit for better survival. These histopathological changes can alter various physiological behavioural and enzymatic activities of the fish. 


$$
\text { PLATE-I. }
$$

Gill 96 hrs (Cirrhinus mrigala)

\section{Fig.1. Control}

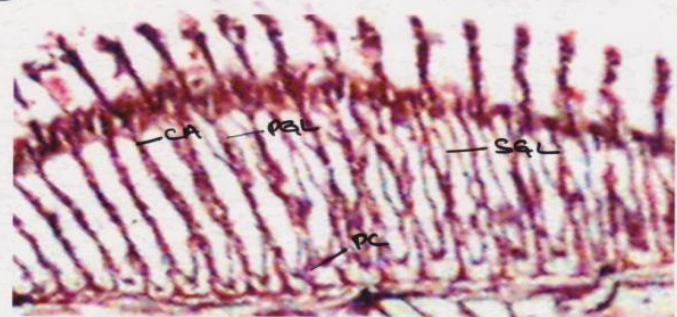

Fig-2. Sublethal

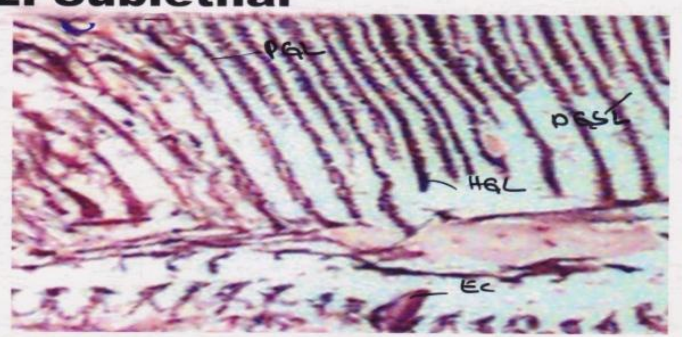

\section{Fig-3. Lethal}

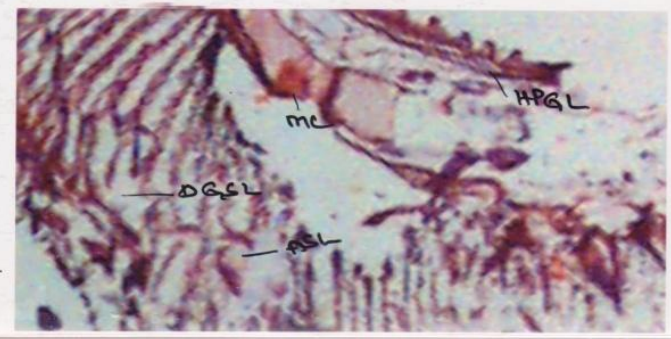

\section{PLATE-II.}

Liver 96 hrs (Cirrhinus mrigala)

Fig.1. Control

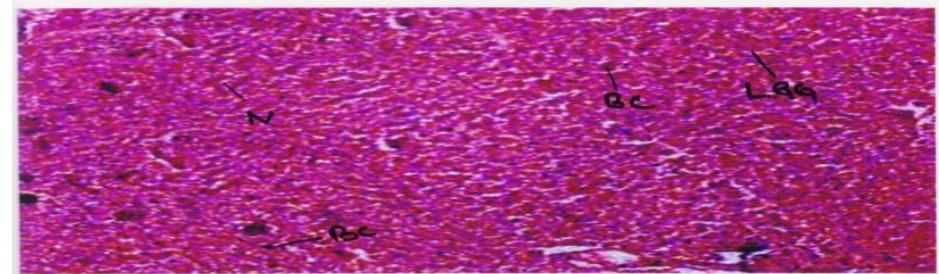

Fig.2. Sublethal

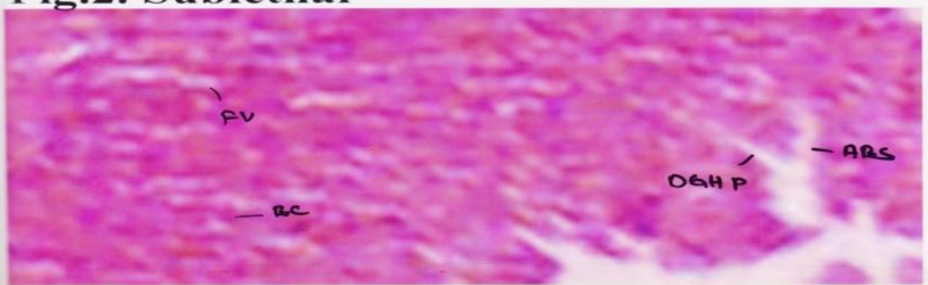

Fig.3. Lethal

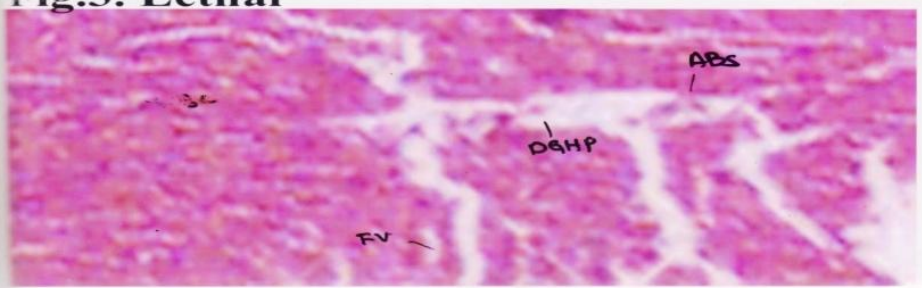




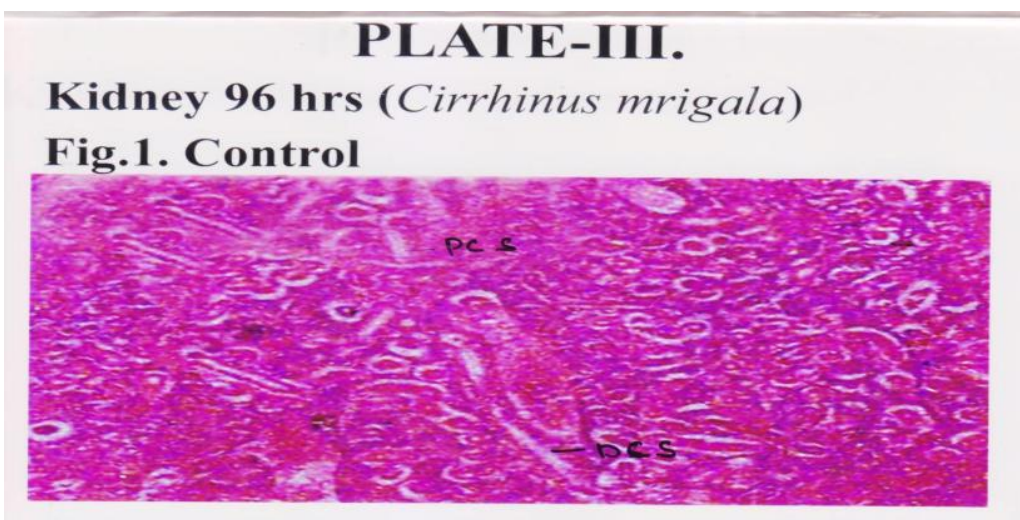

Fig.2. Sublethal

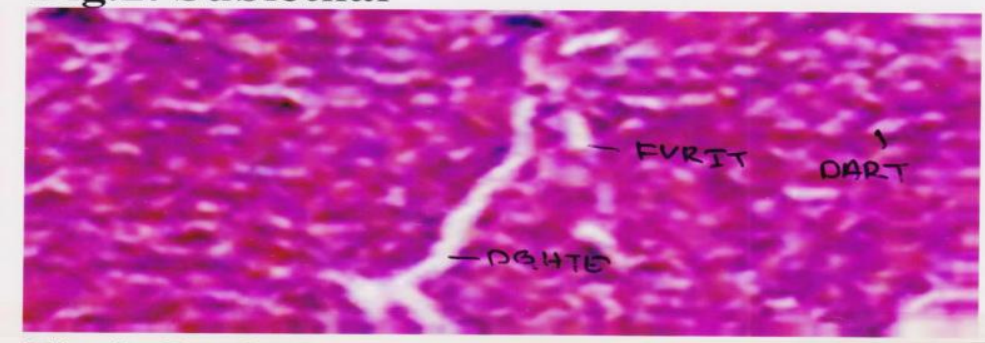

\section{Fig.3. Lethal}

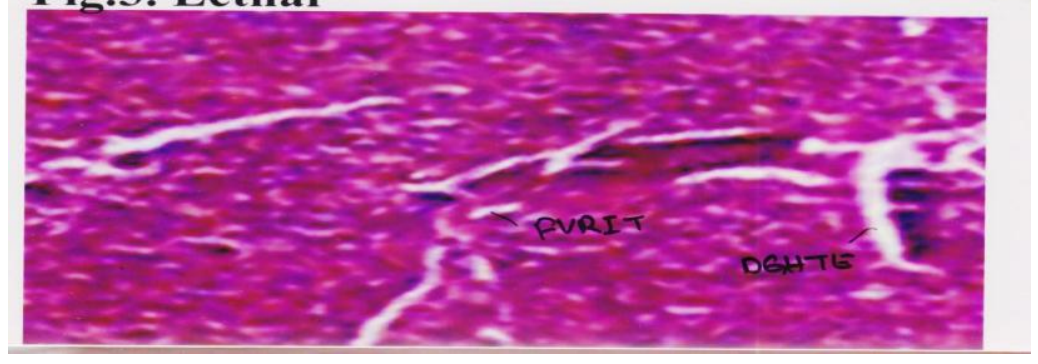

\section{Conclusion}

The present study was undertaken to assess the effect of pyrethroid insecticide cypermethrin on a nontarget organism - fish, cirrhinus mrigala The fish affected by the pesticides could pose a health problem the consumers. Hence, it is worthwhile to investigate the effect of the pesticides on the fish like cirrhinus mrigala. Of the several pesticides used, the cypermethrin toxicity and its effect on cirrhinus mrigala is not so far investigated. The oxygen concumption of the exposed fish cirrhinus mrigala Was found to be declined gradually till the end of exposure period (24),the gradual decline was attributed to the interference of cypermethrin with oxidative metabolism and also due to the histopathalogical changes that occurred in the gill anatomy. Degeneration, bulging of tips of primary gill lamellae, club shaped secondary gill lamellae, and other severe necrotic changes in the epithelial cells of secondary gill lamellae All these changes indicate the hepatotoxic nature of the cypermethrin. Renal excretion is one of the ways of eliminating the non- detoxified toxicant molecule resulting in severe pathological changes haemopoitic tissue, severe necrosis cloudy swelling of renal tubule, disintegration of inter haemorrhage stitial tissue pycnotic nuclei, etc. 


\section{Reference}

[1]. Ansari, et al. ( 1987), Malathion toxicity, pathological changes in the liver of zebra fish Branchydanio rerio (Cyprinidae). Bio.Fisiol. Anim. (Saopaulo ) 11(0): 27-34,

[2]. Anita Susan, T.( 1994.), Toxicity and effect of synthetic pyrethroid fenvalerate on the metabolism of the three Indian major carps Labeo rohita, Catla catla and Cirrhinus mrigala (Ham.), Ph.D. Thesis submitted to Nagarjuna University, A.P., India

[3]. Anitha Kumari and Shree Ram Kumar. (1997), Effect of polluted water on histochemical localization of carbohydrate in a freshwater teleost Channa punctata (Bloch) from Hussain Sagar Lake, Hyderabad, Andhra Pradesh. Poll. Res. 16(3): 197-200,

[4]. Baticodos. M., et. al. (1991),. Effects of gusathion as the survival and shell uality of juvenile Penaeus monodon .Aquaculture, 93 (1): $9-20$,

[5]. Chakraburthy, Gouri and Konar, S.K. (1974). Chronic effects of sublethal levels of pesticides in fish. Proc.Nat.Acad.Sci., India 44B: 241-246.

[6]. Cowey and Roberts (1978). Pesticidal effects written by Rand, G.M, and Petrocelli, Sam, R. (Ed.). (1984). Fundamentals of Aquatic Toxicology

[7]. Duble, M.S. and Shah, P (1979.),. Histopathological lesions induced by Malathion in the liver of the Channa punctatus. Ind. J.Exp. Biol. 17 (7): 693-697,

[8]. Eller, L.L. ,( 1971 ), Gill lesions in freshwater teleosts. In: Riubelin W.E. Migaki, G. (ed.). The pathology of fishes. Univer Wis. Press, 305-330.

[9]. Jones, J.R.E. ,( 1973), Fish and oxygen, pollution by oxygen reducing agents. Fish and River Pollution, Butterworth and Co. 5-26 pp

[10]. Jayantha Rao, K. (1984),. Histopathology as a diagnostic tool in evaluating of toxicity, Environ. Toxicol. Selected lectures and methods, S.V. University, Tirupathi, India,

[11]. Jayantha Rao, K., Madhu, Ch. and Rama Murthy, K. (1985.), Histopathological and histochemical changes under phosphomidon intoxication in liver of fresh water fish. Tilapia mossambica. Proc. Bull. Environ. Sci., 3: 20-23

[12]. Klein (1959). River pollution, Butherwroth and co (publishers) Ltd, 206pp.

[13]. Knowles C.D. and M.J.Mckee (1987) Protein and nucleic acid content in Daphnia magna during chronic exposure of cadmium.Ecotoxicol. Environ.SAF.13(3):290-300.

[14]. Karuppasamy. R. ,(2000), Tissue histopathology of channa punctatus (Bloch) under phenyl mercuric acetate toxicity. Bulletin of pure and Applied Sciences.Vol-19-A(No:2).P.109-116

[15]. Luther Das, V., Raju, K.S. and Kondaiah, K,( 2000),Toxicity and effect of Cypermethrin to fresh water fish Labeo rohita (Hamilton). Proceedings of AEB. 9 (10): 41-48 Murthy, A.S. Toxicity of Pesticides to fish, volume 1 CRC Press, Inc., Bocaraton, 1986

[16]. Lowe, J.I.( 1966.), Proc. $19^{\text {th }}$ Conf. S.E. Association of Fish Comm. Tulsa., Oklahoma, 271,

[17]. Mathur, D.S., Agarwal, M.D. and Rana, P.D (1981),Histopathological changes in liver and intestine of Rana cyanophyticlis (Schron) induced by aldrin. J. Environ. Biol. 2: 105-107,

[18]. McBride, J.R.,Dye, H.M. and Donaldson, E.M. (1981). Stress response of juvelnile sockeye salmon (oncorhynchus nerka) to the butoxyethanol ester (or) 2,4 dichlorophenoxyacetic acid.Bull.Environ.Contam. Toxicol. 27, 877.

[19]. Natarajan, G.M. (, 1981), Effect of lethal $\mathrm{LC}_{50}, 48 \mathrm{~h}$ concentrations of metasystox on selected oxidative enzymes, tissues respiration and histology of gill of freshwater air breathing fish Channa striatus. Curr. Sci. 50(22): 985-991.

[20]. O’Brien, R.D (1967),. In: Insecticides Action and Metabolism, Academic Press, New York,

[21]. Oguri, M. (1982). Atlas of fish histology (ed) Takashi Hibiya.

[22]. Rama Murthy, K. (1988.), Impact of heptachlor on haematological, histological and selected biochemical parameters on freshwater edible fish, Channa punctata (Bloch). Ph.D. Thesis, S.V. University, Tirupathi, India,

[23]. Roy. P.K. and Datta Munshi, J.S. (1991) Malathion induced structural and morphometric changes of gills of a freshwater major carp Cirrhinus mrigala (Ham.). J. Environ. Biol. 12 (1): 79-87.

[24]. Smith,T.M., and stratton, G.W.(1986). Effect of synthetic pyrethroid insecticides on non-target organisms. Residue reviews. 4:103113.

[25]. Tilak, K.S., Veeraiah, K. and Ramana Kumari, G.V. (2001),. Biochemical changes induced in freshwater fish Labeo rohita (Hamilton) exposed to pesticide mixture. Asian J. of Microbiol. Biotech. \& Eng. Sci. Vol.3, No. 4: 315-319,

[26]. Tilak, K.S., Veeraiah, K. and Ramana Kumari, G.V. ( 2001), Toxicity and effect of chlorpyrifos to the freshwater fish Labeo rohita (Hamilton). J. Poll. Res. 20(3): 443-445,

[27]. Tilak.K.S, Koteswararao.Dand Veeraiah.K. ( 2002 ), Effects of chlorpyrifos on Histopathology of the fish Catla catla.J.Ecotoxical. Environ. Monit. 15(2) 127-140,

[28]. Vijayalakshmi (1994.),. Toxicity of monocrotophos and fenvalerate to three Indian major carps Catla catla, Labeo rohita and Cirrhinus mrigala (Hamilton) and the effects of the toxicants on the fish Labeo rohita. Ph.D. Thesis submitted to Nagarjuna University, Guntur, A.P., India,

[29]. Vijayalakshmi, S. and Tilak, K.S. (1996), Effect of pesticides on the gill morphology of Labeo rohita. J. Ecotoxicol. Environ. Monit. 6(1): 59-64,.

[30]. Veeraiah, K. and Durga Prasad, M.K. (1998), Study on the toxic effects of cypermethrin (technical) on organic constituents of freshwater fish. Labeo rohita (Hamilton). Proc. Acad. Environ. Biol. 7(2): 143-148,

[31]. Veeraiah, K. and Durga Prasad, M.K (2001), Studies on ventilatory patterns of fish under normal and stressed conditions using indigenously designed electronic recording instrument. Proceedings of the International Conference of ICIPACT-

[32]. Veeraiah, K. (2002),. Cypermethrin toxicity and its impact on histochemical and histological changes in the Indian major carp. Labeo rohita (Hamilton). Ph.D. Thesis submitted to Nagarjuna University, Nagarjunanagar, Guntur, A.P., India,

[33]. Venkatesam. R and Subramaian. N (2007),. Effect of copper sulphat onhistopathological changes in the fresh water fish Oreochromis mossambicus (peters).J.Ecotoxi.17(4)353-361, 